\title{
El discurso jurídico sobre el caso Romina Tejerina: una mirada en clave de género
}

\author{
The legal discourse on the case Romina Tejerina: a look at key \\ gender
}

María Laura Martinetti ${ }^{1}$

\begin{abstract}
Resumen
El objetivo de este artículo es reponer y problematizar un conjunto de discursos jurídicos referidos al caso Romina Tejerina, atendiendo especialmente a la dimensión generizada de los mismos. Proponemos indagar el modo en el que la figura jurídica de infanticidio opera en tanto configuradora de identidades genéricas y cómo dichas identidades se entrecruzan en el discurso del derecho con otras, histórica y discursivamente constituidas, como la clase y la edad.

El análisis del discurso jurídico se servirá entonces del género en tanto clivaje desde donde pensar las valoraciones que el derecho propone en relación con el cuerpo de las mujeres y, puntualmente, sobre su capacidad reproductiva y las explicaciones propuestas cuando el infanticidio irrumpe en escena.
\end{abstract}

Palabras clave: género - discurso jurídico - maternidad - infanticidio - identidades.

\begin{abstract}
It is the aim of this article to replace and problematize on some legal discourses about the case of Romina Tejerina, providing special attention to the gendered dimension on them. We propose inquire how the legal figure of infanticide operates setting generic identities and how those identities cross at legal discourse with other ones: age and social class.

The analysis of legal discourse will use the gender to think on the judgments that the legal discourse proposes about women's bodies, their reproductive capacity and the explanations for infanticide.
\end{abstract}

Key words: gender - legal discourse - motherhood - infanticide - identities.

Fecha de recepción: 4 de abril de 2012

Fecha de aprobación: 18 de marzo de 2013

Licenciada en Ciencias de la Comunicación, Facultad de Ciencias Sociales, Universidad de Buenos Aires. 
"La fuerza social del Derecho (...) no se limita a la imposición de un comportamiento o a la creación instrumental de un cierto estado de cosas. La fuerza del Derecho también se encuentra en su carácter de discurso legal y de discurso legítimo; en su capacidad para crear representaciones de las cuales se derive un respaldo político; en su aptitud para movilizar a los individuos en beneficio de una idea o de una imagen" (García Villegas [1995: 87] en Segato, 2003: 126).

El presente artículo se propone como instancia de reflexión acerca de ciertos discursos pertenecientes al campo jurídico en relación con el caso Romina Tejerina, una joven jujeña que, en febrero de 2003, mató a la beba que parió en el baño de su casa, tras ocultar su embarazo, producto de una violación. En 2005, Tejerina fue condenada por homicidio calificado por el vínculo a catorce años de prisión.

El corpus utilizado para el análisis incluye los fallos y los fundamentos de las respectivas sentencias correspondientes a las siguientes causas: "Romina Anahí Tejerina, homicidio calificado, San Pedro" (Causa Nro. 29/05), "'"Recurso de hecho deducido por Romina AnahíTejerina en la causa Vargas, Emilio Eduardo s/ p.s.a. de abuso sexual con penetración" $y$ "Recurso de hecho deducido por la defensa de Romina Anahí Tejerina en la causa Tejerina, Romina Anahí s/ homicidio calificado -causa Nro. 29/05-".

Nos interesa especialmente analizar las valoraciones socialmente hegemónicas configuradas históricamente por el campo jurídico en torno a las mujeres, sus cuerpos, sus modos de sentir y ejercer la maternidad, sus prácticas sexuales. Asimismo, indagaremos algunos aspectos de la tematización judicial del infanticidio que retoman elementos de otros campos discursivos, igualmente hegemónicos, tales como el médico y el religioso.

El trabajo de análisis se servirá entonces de los aportes del campo de los estudios de género y sexualidades. Desde allí es que planteamos la necesidad de problematizar los decibles que el derecho propone frente al caso Tejerina, procurando ubicar lo sucedido en el marco de un orden social, cultural y político. Las operaciones problemáticas identificadas al analizar los documentos jurídicos que integran el corpus nos conducen a repensar la figura del infanticidio y los elementos que en ella funcionan a modo de configuradores de identidades genéricas, tanto femeninas como masculinas.

Proponemos destacar la importancia de incorporar el género en tanto clivaje desde donde abordar el discurso jurídico sobre el caso Tejerina, lo que proporcionará las herramientas necesarias para entender, por un lado, el papel que el discurso hegemónico androcéntrico ${ }^{2}$ juega en la naturalización y/o reproducción de la violencia de género y, por otro lado, el modo en que las mujeres son evaluadas en relación con su

Cuando hablamos de androcentrismo nos referimos al "supuesto que considera lo propio y característico de los hombres como parámetro de descripción, evaluación y análisis de la realidad y la experiencia humana en su totalidad. Confunde el concepto de 'humanidad'con el de 'hombre-varón', reduciéndolo a él" (Área Queer, 2007) 
mayor o menor cercanía con los estereotipos de género ${ }^{3}$. Y, en este sentido, veremos que la maternidad cumple un papel especialmente relevante en la producción de clasificaciones.

Asimismo, teniendo en cuenta que el género opera entrecruzado con otras categorías identitarias discursivamente construidas, señalamos la importancia de indagar el cruce entre género y clase social, que atraviesa el tratamiento jurídico del infanticidio cometido por Tejerina. Se trata de una joven perteneciente a las clases populares y la opresión, como producto de relaciones sociales específicas (Rubin, 1986), es el elemento común a ambas condiciones subalternas: ser mujer y pertenecer a las clases populares. Partir de considerar la subalternidad en el marco de un sistema social y cultural, contra cualquier tipo de explicación biológica o simplemente "natural", nos ubica frente a la necesidad de desentrañar la "recíproca interdependencia de la sexualidad, la economía y la política" (Rubin, ídem: 141) que históricamente configura tales sistemas. Así, una de las preguntas desde las cuales abordamos el corpus se propone pensar de qué modo su condición genérica en cruce con la pertinencia a las clases populares ubica a Romina Tejerina en un lugar específico de valoración social en el seno del discurso jurídico que la condena.

Otro de los ejes a problematizar será el que surge a partir de vincular la pertinencia de género y de clase a la dimensión etaria. Romina pertenece a los sectores populares y, además, es una joven (tenía 19 años cuando dio a luz). Siguiendo a Chaves (2005), las miradas hegemónicas sobre la juventud y los estereotipos que estas construyen y fijan van a variar en relación con la posición de clase. Elizalde (2011) también destaca el modo en el que las jóvenes pobres se constituyen en objeto de ciertas formas de representación que ponen en escena un modo de ser esencialmente problemático, a la vez que dicha condición problemática se ve exacerbada en los casos de jóvenes pobres que se embarazan (Elizalde, ídem). De ahí que nos interese abordar entonces de qué modo esta condición etaria, que constituye un tercer eje de subordinación, configura y propicia ciertas lecturas e interpretaciones al interior del cuerpo del derecho.

\section{MUJERES-MADRES: UN BINOMIO DIFÍCIL DE QUEBRAR}

El vínculo mujeres-derecho se ha construido históricamente a partir de una supuesta necesidad de "normatizar y ordenar los comportamientos femeninos, presumiblemente determinados por la compleja y débil fisiología de las mujeres" (Ini, 2000: 236). La relación se va a fundar a base de una cierta condición desordenada inherente a las mujeres, sus cerebros y sus cuerpos y, a partir de allí, se irá moldeando un tipo particular de discurso jurídico que, en su definición de la feminidad, va a servir a su construcción y limitación. El temor y la incertidumbre frente a los desórdenes femeninos, anclados en

3 Nos interesa el abordaje de la noción de estereotipo en tanto elementos de construcción de sentido, expresiones de un imaginario social, que van a cobrar especial relevancia como mediadores en la relación que se establece entre una determinada imagen colectiva en circulación, la constitución de la identidad social y la definición de las interacciones (Amossy y Herschberg Pierrot, 2010). 
la supuesta endeble condición biológica de las mujeres, se constituyó en el fundamento del sometimiento jurídico, acompañado también de la inferioridad jurídica respecto de los varones, que padecieron las mujeres a lo largo del tiempo (Barrancos, 2000). En este sentido, las mujeres no son simples sujetos de derechos para el discurso judicial, sino que "su estatus está siempre imbuido de significados culturales específicos que surgen de su género" (Daich, 2008: 63).

En este marco de sujeción e inferioridad, el ejercicio de la maternidad va a ocupar un lugar especialmente relevante en el tratamiento de los casos judiciales protagonizados por mujeres en su calidad de autoras de delitos, especialmente en casos de mujeres que matan a sus bebés recién nacidos. La capacidad reproductiva de las mujeres instituye entonces un deber ser que no será fácilmente eludible ni revocable para las mujeres. Así, el derecho, antes que sujetos de derechos, va a proceder a juzgar madres o potenciales madres, evaluadas y clasificadas en función de una representación ideal, encarnada por la "buena madre": instintivamente maternal, amorosa, sacrificada y gustosamente entregada a la maternidad (Daich, 2008). Este ideal se va a fundir armoniosamente con la delimitación social establecida en el derecho liberal, vinculada a la exclusión de las mujeres del ámbito del espacio público y su confinamiento a la esfera privada del hogar familiar en nombre de su "natural" disposición a la función materna, a la vez que se corresponde con el modelo de mujer-madre propuesto por el catolicismo a lo largo del siglo XIX, apoyado en tres rasgos principales: fortaleza, virtud y sacrificio (Correa, 2000).

Las mujeres que cometen infanticidio van a ser juzgadas entonces por un dispositivo legal y discursivo que las define en tanto madres. Y cabe destacar el carácter problemático de este hecho si tenemos en cuenta que es precisamente la experiencia de maternidad lo que no fue posible para ellas: "el infanticidio es un acto extremo que (...) reafirma una maternidad rechazada en un tiempo y lugar determinados en la biografía de una mujer" (Kalinsky y Cañete, 2010: 40).

No obstante, como bien preguntan Caamaño Murúa y Rangel Núñez, "¿cómo hablar de rechazo a la maternidad en una institución [la jurídica] que vive de su imagen idealizada?" (2002: 74). Y, paradójicamente, la maternidad también será la vía propuesta como criterio de "reivindicación" o "rehabilitación" dentro del ámbito penitenciario.

\section{MUJERES ASESINAS: EL DELITO DE INFANTICIDIO}

La figura jurídica de infanticidio aparece ya en el primer Código Penal de Argentina, redactado por Carlos Tejedor en 1870, donde se la definía como la muerte de un recién nacido (de hasta tres días de vida) en manos de su madre con el propósito de ocultar su deshonra y bajo la influencia del estado puerperal, y se extendía también a los abuelos maternos que cometieran el delito para ocultar la deshonra de su hija, debiendo cumplir una pena de tres a seis años de prisión (Daich, 2008; Nari, 2004). Idéntica definición del infanticidio aparece en el Código de 1887. En los años siguientes, tras posteriores modificaciones, se extendió la figura y pasó a alcanzar, además de a 
los padres de la mujer, a los hermanos, marido e hijos; al mismo tiempo, la limitación de hasta tres días en relación con el estado puerperal se excluyó y pasó a considerarse un lapso de tiempo indeterminado. Varias modificaciones se fueron sucediendo sobre el infanticidio a lo largo del tiempo. En 1967, por ejemplo, se aumentó la pena para la mujer y se excluyó a los parientes del privilegio de atenuación, lo que quedó sin efecto en 1973, hasta que volvió a restablecerse en 1976. Esta última modificación fue derogada en 1984 (decreto 3992/84) y la figura de infanticidio estuvo vigente hasta enero de 1995, fecha en la que se sancionó la Ley No 24410, que modificaba el Código Penal y el Código Procesal Penal de la Nación.

La muerte de un niño o niña en manos de su madre ha sido reemplazada, desde entonces, por la figura de homicidio agravado por el vínculo, que contempla la posibilidad de aplicar la pena máxima de reclusión perpetua, a menos que se identifiquen circunstancias extraordinarias de atenuación. "Ni la honra ni el honor se comprometen hoy en el parto" : tal fue el argumento utilizado en la Cámara de Senadores durante 1994, al discutirse la derogación de la figura del infanticidio. Los legisladores consideraron en ese momento que se trataba de una figura que, si bien había resultado coherente a fines del siglo XIX, al sancionar el Código, se había tornado anacrónica con el paso de los años en tanto que la maternidad fuera del matrimonio ya no comprometía el honor de la mujer ni la "condenaba a una muerte social" (Kalinsky y Cañete, 2010: 13). Asimismo, la derogación del infanticidio se enmarcaba en un contexto de reforma de la Constitución Nacional que reconoció jerarquía constitucional a los tratados internacionales firmados por Argentina en materia de derechos humanos; entre ellos, la Convención Internacional por los Derechos del Niño. Esta incorporación fue clave a la hora de concluir en que la vida de los niños constituía un bien jurídico superior a la protección legal de la honra pública de las mujeres y sus familias. A este escenario deberá agregarse el finalmente fallido intento del entonces presidente Carlos Menem de incorporar a la nueva Constitución un artículo que garantice la protección de la vida desde la concepción. El exmandatorio deberá conformarse con incorporar al calendario, por medio de un decreto, el Día del Niño por Nacer (Pecheny, 2006).

Nos interesa especialmente problematizar cuáles son los elementos que el discurso jurídico propuso históricamente para la aplicación de la figura atenuada que comporta el delito de infanticidio. Si bien la culpabilidad de las mujeres por la muerte de su hija o hijo nunca fue puesta en duda, una ley que contempla el infanticidio no deja de atender los motivos que las conducen a cometer este delito. Dichos motivos se vinculan, por un lado, al resguardo del honor de la mujer infanticida y, no menos importante, de los varones vinculados a ella y, por otro lado, a la influencia del estado puerperal, elemento que propone una explicación del crimen por la locura, las alteraciones nerviosas y debilidades mismas del sexo femenino (Nari, 2004).

Al analizar los fundamentos de la pena atenuada que el infanticidio comporta, encontramos, por un lado, el vínculo histórica y discursivamente construido entre honor y maternidad. La vergüenza que producía ser una madre ilegítima, con la consecuente 
deshonra que eso implicaba para los varones vinculados a ella -padre o marido, principalmente-, era considerada un sentimiento bueno, válido, aun cuando ocasionaba la muerte del niño o niña (Daich, 2008). De ahí que la voluntad de proteger esa deshonra (personal y familiar) resultara un atenuante ante la Justicia. Ahora bien, un modo tal de concebir la cuestión no pretende proteger a las mujeres en su individualidad y su derecho ciudadano, sino que busca poner a resguardo un sistema de estatus en el que los varones ven afectada su integridad moral como consecuencia de las acciones de las mujeres vinculadas a ellos (Segato, 2003).

Una conceptualización de la honra femenina vinculada a la regularidad o irregularidad de la maternidad encuentra sus condiciones de producción en una serie de discursos, históricamente producidos, tanto por el ideario patriarcal como por la tradición religiosa judeo-cristiana, en relación con la sobrevaloración de la maternidad, por un lado, y la desvalorización de la sexualidad erótica femenina, por otro (Caamaño Murúa y Rangel Núñez, 2002). Así, nos encontramos frente a una naturalizada e inquebrantable díada feminidad-maternidad, cuyo sustento biológico resulta incuestionado e incuestionable. Al mismo tiempo, el ejercicio de la sexualidad se plantea como válido dentro del matrimonio y con fines de procreación y toda mujer que transgrede tales representaciones y valores considerablemente arraigados en el imaginario social deja de ser una mujer "honesta" (esposa-madre-asexual) para convertirse en "deshonesta" (mujer-prostituta-sexual) (Ídem). La honra se vincula entonces a un uso específico del cuerpo, que se hará carne en el embarazo, y que finalmente, al atravesar el tamiz del imaginario social dominante y de las representaciones subjetivas que su internalización a modo de "deber ser" plantea, genera culpa, vergüenza y las lleva a cometer un crimen que, aunque objeto de castigo, encuentra su atenuación en el reconocimiento subjetivo del desvío. En resumen, la pena es menor porque la mujer infanticida sintió vergüenza de lo que hizo.

Esta conceptualización de la honra vinculada a la vergüenza y el arrepentimiento por haber hecho un uso "indebido" del propio cuerpo, obtura cualquier intento de hacer visibles los diversos tipos de violencias que padecen las mujeres que cometen infanticidio. En este sentido, es posible identificar un patrón persistente históricamente en torno a los casos de infanticidio que se vincula a embarazos no deseados, muchas veces originados a partir de una violación (Haustafer y Ardy [1984], Lazarus [1994] en Kalinsky y Cañete, 2010). Frente a un escenario tal, cabe preguntarnos: ¿son las mujeres violadas menos "honestas" ? ¿Acaso es comprensible que quieran ocultar la deshonra que la violación les ocasiona? Estos interrogantes adquieren sentido en el marco de un imaginario social en el que prevalece el estereotipo de la mujer que provoca la violación. Y lo hace precisamente mediante un uso específico del propio cuerpo: usa pollera corta, sale sola de noche. O, como dice una sentencia condenatoria citada por Kalinsky y Cañete, "aprovecha su contextura de labios carnosos que al decir policial es agradable para los hombres" (2010: 66).

Así, la definición jurídica de infanticidio en relación con el requisito de ocultamiento de la deshonra conlleva un componente estigmatizante, que se verá reforzado cuando 
la condición de "ser mujer" se cruza con otra definición identitaria igualmente subalternizante: ser pobre. A modo de ejemplo:

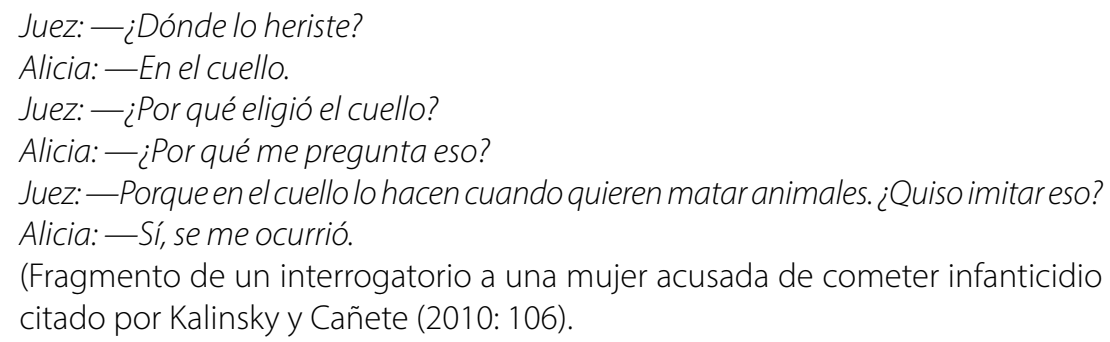

Y, más adelante, los autores sostienen: "Ella quiere contar sobre su vida pero ellos se preocupan por compararla con un animal, ya que es del campo y encima indígena" (Ídem: 107). Este tipo de tratamiento del caso da cuenta de que el derecho se posiciona no solo desde un lugar patriarcal, sino también desde una superioridad de clase (Ini, 2000). Al analizar los documentos jurídicos que integran el corpus, veremos de qué modo el cruce entre ambas categorías identitarias (ser mujer y ser pobre) opera en el caso de Romina Tejerina, configurando un tipo de discurso jurídico estigmatizante.

El segundo elemento que funciona como atenuante para el infanticidio es la influencia del estado puerperal, que constituye otro argumento notablemente estigmatizante: la atenuación se funda en una "patológica esencia femenina" (Ini, 2000: 238), en una inestabilidad que se ve agudizada sobre todo en el momento del parto y que da cuenta de la influencia de las interpretaciones hegemónicas del saber médico en relación con el cuerpo femenino (Ben, 2000). En este sentido, la delimitación de la feminidad propuesta por el discurso médico ya desde fines del siglo XIX abarcaba no solo aspectos referidos a procesos biológicos, sino también aspectos comportamentales: "desde la cuestión de la maternidad o el trabajo femenino hasta el tipo de vestidos más convenientes según la Higiene" (Ídem: 254). Tomando como fundamento su raíz anatómica, la maternidad fue considerada como

(...) tarea adecuada para la psiquis de la mujer, cuyo cerebro, supuestamente menor que el de los varones, menos pesado y vascular, originaría ciertas características atribuidas exclusivamente a ellas: "sensibilidad extremada", imaginación muy viva, atención y reflexión más constante y menos profunda, juicio más pronto y guiado por aquella exquisita sensibilidad y no por la razón. En la mujer, el amor, las facultades afectivas y la abnegación estaban más desarrolladas que en el varón; en cambio, las facultades morales eran menores, al igual que la ambición (Ídem. 254).

Y, como sostiene Ben,

(...) el presupuesto en el que se basa este discurso es el de la "correlación entre la locura y los desórdenes del aparato genital"; por esta razón, tanto la menstruación como cualquier alteración del funcionamiento normal se consideraban potenciales generadoras de efectos psíquicos negativos (2000: 258). 
Específicamente en relación con el embarazo, se sostenía que el estado puerperal provocaba "disturbios del sistema nervioso: agotamiento físico, agotamiento mundano, recuerdos de sus fastidios si la mujer es primípara, complicaciones, temores de hemorragia, de infecciones sépticas, inaptitud para alimentar..." (Tomilson [1902] en Ben, 2000: 259). Tal sintomatología, encuadrada por supuesto en el terreno de la patología, convertía a todas aquellas mujeres que rechazaban la fatalidad objetiva que encarnaba la maternidad en víctimas de la llamada "psicosis puerperal". Esta expresión ofrecía así una cuota de tranquilidad, cargada de supuesto rigor científico, ante la realidad de hechos que desafiaban el mandato de la maternidad. Nuevamente, al igual que en relación con el ocultamiento de la deshonra, los argumentos se basan en interpretaciones de un cuerpo femenino problemático y desordenado.

Resulta pertinente advertir de qué modo el discurso jurídico continúa sirviéndose aquí del binomio feminidad-maternidad. Las mujeres siguen siendo naturalmente madres, es por eso que cuando matan a sus hijos es porque, como resultado de la peligrosa biología femenina, están locas (Daich, 2008). Este planteo continúa ejerciendo su influencia en el marco del debate actual por la restitución del infanticidio al Código Penal ${ }^{4}$. Si bien hay acuerdo sobre la falta de vigencia de la idea de deshonra en relación con la "maternidad irregular" que motivó su derogación en el 95, la presencia de alteraciones propias del estado puerperal aún subsiste en el encuadre de figuras como la "emoción violenta" o bajo la influencia de "circunstancias extraordinarias de atenuación" (Ídem).

\section{EL CASO TEJERINA: SOBRE LAS CIRCUNSTANCIAS EXTRAORDINARIAS DE ATENUACIÓN}

Romina Tejerina tenía 19 años cuando un vecino de San Pedro de Jujuy, el pueblo donde vivía, la violó a la salida de un baile en agosto de 2002. En febrero de 2003, Romina dio a luz una beba, a quien mató minutos después de haberla parido en el baño de la casa donde vivía con sus hermanas. Había ocultado su embarazo con tan solo una faja; nadie de su entorno se había dado cuenta de que estaba embarazada.

La joven intentó varias veces sin éxito provocarse un aborto mediante métodos "caseros". También intentó que le practicaran un aborto clandestino, del que finalmente desistió por no poder pagar los trescientos pesos que el médico le pedía. Mientras tanto, el embarazo avanzaba y su vecino, Eduardo Vargas, continuaba viviendo en la casa contigua a la suya.

En este contexto, signado por la violencia, la negación, la humillación y la exclusión, tiene lugar el nacimiento y la posterior muerte de la beba. Romina quedó inmediatamente detenida. En 2005, cuando llevaba ya dos años presa, tuvo lugar el juicio oral y el dictado de sentencia: pese a que la fiscalía solicitó la pena de cadena perpetua,

$4 \quad$ Cabe señalar que en septiembre de 2010 obtuvo media sanción en la Cámara de Diputados un proyecto de ley que propone la restitución del infanticidio al Código Penal. 
se condenó a la joven a catorce años de prisión que resultan de la consideración, por parte del tribunal, de circunstancias extraordinarias de atenuación. La pena se relaciona con la derogación de la figura de infanticidio en 1994. Como consecuencia de tal derogación, Romina debía ser juzgada por homicidio calificado, agravado por el vínculo (art. 80 inc. 1 del Código Penal), delito para el que se prevé la pena máxima de prisión perpetua, a menos que existan atenuantes. Días después del dictado de sentencia, se dieron a conocer los fundamentos de la misma, donde se explicitaron los motivos de la sentencia y las circunstancias consideradas como atenuantes ${ }^{5}$. Consideramos que resulta productivo y necesario detenernos en el análisis del documento correspondiente a la exposición de tales fundamentos, en tanto, como veremos, retoma los elementos constitutivos de la derogada figura de infanticidio, a la vez que agregan otros atenuantes, distintos, pero igualmente estigmatizantes.

Así, el documento sentencia que "existen circunstancias previas y concomitantes al momento del desenlace letal, que llevan a la encartada a cometer el homicidio de su beba recién nacida"y continúa con su seguida enumeración:

- "Vivió una infancia plagada de violencia, tanto física como moral". Se sostiene que el eje de la violencia era su núcleo familiar y que, justamente por tales padecimientos, no vivía con sus padres. Se resalta, asimismo, que de los informes periciales se desprende que "los padres de la procesada no tuvieron la capacidad para contener a su hija" y que esa falta de apoyo "actuó como disparador de la conducta" de Romina. Así, si bien se menciona que la historia de violencia familiar vivida "tuvo relevancia en la posición que tomó por el embarazo", el foco se coloca, al explicar el punto, en la situación de desamparo en la que queda Romina como consecuencia del abandono de la casa de sus padres. Ese desamparo, que puede leerse en el marco de las interpretaciones hegemónicas propuestas en el discurso del derecho como ausencia de vigilancia, es lo que dispara su conducta.

- "Se encontraba sola, esperando un niño sin padre (al menos conocido), no tenía apoyo familiar". Nuevamente, se plantea el desamparo en el que se encontraba la joven. Y a la ausencia de vigilancia paterna, se suma la falta de un marido. La expresión "niño sin padre" da cuenta de la invisibilización de la violación, algo que para la Justicia nunca existió; de ahí que se llegue a plantear que el niño no tiene padre. Y la aclaración "al menos conocido" alude a cierta condición de liberalidad sexual por parte de Romina, a la vez que actualiza esa maternidad irregular a la que se refería la legislación sobre infanticidio de fines del siglo XIX. Por otro lado, nos interesa especialmente poner de relieve de qué modo el atenuante presentado en este punto pone en escena cierto prejuicio que "recae sobre las jóvenes pobres 'que se embarazan', ya que no solamente se ponen tácitamente en duda sus habilidades como madres sino que se sospecha de su

5 Los fundamentos de la sentencia y el detalle de los atenuantes puede encontrarse en versión digital (Diario Judicial, 2005) 
moralidad y se castiga socialmente'la imprudencia' de traer niños al mundo sin el respaldo de un padre proveedor" (McRobbie [2000], en Elizalde, 2011: 137). Si bien en este caso las consideraciones se exponen en términos de circunstancia de atenuación, no por ello debemos obviar su carácter violento y estigmatizante.

- "Al momento del alumbramiento Tejerina se encontraba en la soledad del baño de la casa de su hermana (...) privada de los medios asistenciales y farmacológicos indispensables". Encontramos aquí la referencia a uno de los elementos que componen cierto patrón persistente que reviste el infanticidio a lo largo del tiempo: "el parto suele ser en la casa, casi siempre de noche o al amanecer, sin asistencia..." (Castex [2008] en Kalinsky y Cañete, 2010: 28). No obstante, si bien el discurso jurídico se cierne sobre ciertas especificidades del infanticidio que se relacionan con el entramado social que rodea las biografías de las mujeres que lo cometen, al mismo tiempo se retoman elementos que provienen de una concepción del cuerpo femenino como objeto de ejercicio de un poder a la vez represivo y configurativo (Caamaño Murúa y Rangel Núñez, 2002). Nos referimos, en este caso, a la naturalización de los procesos de institucionalización y medicalización del parto que, lejos de haber existido siempre y de forma inmutable a lo largo del tiempo, son el resultado del empoderamiento del saber médico a lo largo de los siglos XIX y XX sobre los cuerpos femeninos y, más específicamente, sobre su capacidad reproductiva. Tal como sostiene Correa

\begin{abstract}
Como consecuencia de este proceso, se modificó la relación habitual de las mujeres con sus embarazos y sus partos, porque dejó de vérselos como hechos gobernados por la propia fisiología femenina (...) y la relación que la mujer estableció con ellos fue precisamente de incapacidad, extrañamiento y temor. A partir de entonces, embarazo y parto fueron para las mujeres una permanente fuente de hipocondría en la que supo abrevar el poder médico (2000: 194).
\end{abstract}

Así, en los fundamentos de sentencia se plantea como atenuante la falta de hospitalización en el parto de Tejerina, nuevamente, porque lo que está en juego aquí es la falta de vigilancia sobre su accionar y su cuerpo. Si no contaba con un padre ni con un marido ni con un médico que la controle, el desenlace se plantea finalmente como una fatalidad inevitable, como destino ineludible. Y esto se asienta en que

"en el imaginario social y judicial, una buena madre es, entre otras cosas, un sujeto objeto de la ciencia médica (...) Así, pues, desde que los partos fueron apropiados por el poder médico, se espera que las mujeres, en el buen cumplimiento de mandato 'natural', controlen médicamente sus embarazos y partos..." (Daich, 2008: 73-74).

- "Carecía de vivienda y recursos propios". Este punto hace referencia a la condición de clase de la joven. Consideramos que esta referencia a la carencia de vivienda y recursos se funda más en un propósito de estigmatización, con raíces en imágenes estereotipadas de amplia circulación social que asocian pobreza con delincuencia y peligrosidad social, que plantean un paralelismo entre la falta de recursos materiales y simbólicos. La sola referencia a las carencias materiales invisibiliza 
otro tipo de injusticias, igualmente importantes que una desigual distribución de recursos: la"falta de patrones institucionalizados de valores culturales que expresen igual respeto para todos los participantes y aseguren igualdad de oportunidades para obtener estima social" (Fraser, 20026). Así, las instituciones sociales, como el sistema jurídico, son las que, por medio de sus prácticas y discursos, transmiten formas de reconocimiento erróneo mediante la aplicación de los patrones de valor cultural que rigen su funcionamiento. En este caso, hablamos de valores androcéntricos, y elitistas respecto de la clase.

- "Vivió su embarazo con angustia y temor". En relación con el embarazo, se hace referencia a su "ocultamiento parcial" (ya que solo su hermana Érica estaba al tanto), otro elemento de los citados por Kalinsky y Cañete en relación con el patrón que comporta el delito de infanticidio. El documento también refiere a que "el estado de gestación no debía ser conocido, salir a la luz, ya que todos los mensajes y respuestas que obtuvo tenían el sentido de la supresión de la vida, en este caso antes del suceso se sitúan las maniobras abortivas". Y el relato prosigue: "El bebé es experimentado como un cuerpo extraño, siendo incapaz la joven de establecer una relación materno filial. No lo puede reconocer como un hijo. El acto delictivo fue el resultado psicogenético de una reacción secundaria a un desarrollo conflictivo".

Asimismo, se menciona que el estado emocional de Romina "antes y durante el ilícito perpetrado, era de un elevado nivel de tensión". Estas referencias a estados de angustia, tensión, a resultados psicogenéticos, dan cuenta de la confluencia entre el discurso psiquiátrico y criminológico, que construye una escena en la que las mujeres ven reducidas sus penas a costa de convertirse en "enajenadas mentales" (Caamaño Murúa y Rangel Núñez, 2008).

- "Desórdenes psíquicos lógicos motivados durante el curso del embarazo y el alumbramiento". Un planteo tal encuentra sus condiciones de posibilidad en la configuración del cuerpo femenino propuesta por el saber médico, presentada en el apartado anterior. El adjetivo "lógicos" refiere a un cierto rigor científico, que supuestamente avala lo que se afirma. Nuevamente, nos encontramos frente a un discurso psiquiatrizante y patologizante, para el cual la locura proporciona una explicación válida frente a lo que de otro modo no puede explicarse.

- "Joven sin rumbo, sin horizontes, sin objetivos, sin la educación mínima indispensable". Las características que aquí se adjudican a Romina poseen un componente marcadamente estigmatizante, que se vincula a su pertenencia de clase. ¿Cuáles son los elementos para sostener que se trataba de una joven sin rumbo y sin educación? Romina estaba terminando la secundaria cuando dio a luz, hablamos de una joven casi totalmente escolarizada. De ahí que nos preguntemos si se diría lo mismo de ella si se tratase de una joven de clase media 
que cursa el quinto año. Sostenemos que si bien se construye una escena en donde la falta de educación y de objetivos se plantean como circunstancias que atenúan la condena de la joven, no podemos dejar de advertir el hecho de que tales argumentos reproducen procesos de construcción de subjetividades que actualizan formas de dominación y subordinación, tanto de género como de clase.

- "No posee antecedentes policiales y judiciales". Por último, se plantea como atenuante que en "el campo de la delincuencia resulta primaria".

Concluimos que los atenuantes considerados no solo conllevan un notable componente estigmatizante, sino que también confluyen en un último propósito, exitosamente llevado a cabo a lo largo de los años: la invisibilización de la violencia ejercida sobre las mujeres, que encuentra sus condiciones de posibilidad en un escenario de naturalización y aceptación social de la misma.

\section{LA VIOLENCIA INVISIBLE Y LA CONSTITUCIÓN DE UN CUERPO-PROBLEMA}

Otro de los documentos que conforma nuestro corpus de análisis es el recurso de hecho presentado ante la Corte Suprema de la Nación contra la resolución de la cámara de apelaciones del Tribunal Superior de Jujuy, que confirmó el sobreseimiento de Emilio Eduardo Vargas en la causa por abuso sexual con penetración. Consideramos que el análisis de este documento nos proporciona elementos para reflexionar acerca del modo en el que la violación se suprime definitivamente de la escena correspondiente al caso Tejerina.

En el escrito donde consta el rechazo del recurso por parte de la Corte Suprema puede leerse, en primer lugar, el señalamiento de la condición de "detenida, imputada de haber matado a su hijo recién nacido" de Romina "al momento de realizar la denuncia de violación" contra Vargas. Una referencia tal constituye un primer elemento en pos del cuestionamiento de la figura de Romina (estaba ella misma detenida cuando denunció que la habían violado) y, por tanto, de la veracidad de la denuncia efectuada por la joven. Asimismo, se lee:

\section{(...) el fallo evidencia un cotejo acertado de la prueba de testigos y un razonamiento que justifica concluir en que el imputado no se encontraba en el lugar del hecho el día que la denunciante dijo haber sido agredida sexualmente, que esta no fue su única relación sexual y que la hija de la denunciante no fue concebida en la fecha que dijo haber sido violada.}

La referencia a "que esta no fue su única relación sexual" alude a una histórica vigilancia sobre el ejercicio de la sexualidad por parte de las mujeres. ¿Por qué motivo la vida sexual de Romina debe ser objeto de cuantificación? ¿Qué incidencia tendría 
sobre la violación si la joven protagonizó una o más relaciones sexuales? ¿Es que el haber tenido más de una pareja sexual justificaría la violación? Si le gustaba tener relaciones sexuales o si había estado con más de un hombre, ¿eso la convertía en virtualmente disponible para todos los hombres? Estos interrogantes resuenan en un escenario en el que la vigilancia sobre el desorden y la liberalidad sexual de las mujeres aparecen como objeto preferencial de los jueces al momento de resolver casos de abuso sexual. En este sentido, sostenemos que el esquema planteado por Segato en relación con la existencia de una "estructura dialógica, en el sentido bajtiniano, entre el violador y otros genéricos, pobladores del imaginario, en la cual encuentra su sentido la violación, entendida como acto expresivo revelador de significados"(2003: 35), puede pensarse vinculado al sistema jurídico que condena tanto los casos de abuso como a las mujeres infanticidas. El imaginario de esos jueces, su "horizonte mental" en palabras de Segato (ídem), también se encuentra poblado por otros genéricos, con sus mandatos y expectativas. De ahí que propongamos, desde esta perspectiva, entender las condenas impuestas por ellos en tanto reveladoras de significados, en un marco de relaciones entre los géneros que implica posiciones desigualmente provistas de poder.

El caso de Romina Tejerina encarna, en este sentido, una particularidad: conjuga una causa por violación con una causa por homicidio calificado (que, hasta 1995, se hubiera tipificado como infanticidio). Una de las principales expectativas de esos otros genéricos que acompañan el imaginario del derecho al abordar tanto casos de abuso como casos de infanticidio se relaciona con la conceptualización del cuerpo de las mujeres en tanto locus privilegiado de control social, sobre el que en ocasiones se pide que los jueces asuman el rol que maridos o padres no han podido asumir (Ini, 2000).

Nos interesa plantear y problematizar el hecho de que esta constitución de un cuerpo-problema que necesita vigilancia se realiza, en el ámbito jurídico, tanto desde la parte que condena a Tejerina, como también desde su defensa. Resulta oportuno detenernos entonces en esta particularidad con el objeto de analizar en qué medida los propósitos exculpatorios que rodean los casos de infanticidio no logran escapar a las explicaciones reduccionistas, que niegan o invisibilizan la violencia y erigen el cuerpo de las mujeres en tanto objeto de control y dominación social. El rol del "padrecastigador" (postura correctiva) que encarnan los jueces es asumido por la defensa pero en tanto "padre-protector" (postura paternalista), que bregará por piedad para con la incapacidad de sus defendidas para hacerse cargo de sus actos (sexuales y criminales) (Ini, ídem). Así, aun los pedidos de exculpación se sustentan en y recrean estereotipos que, lejos de aportar un beneficio a las mujeres, obstruyen cualquier intento de lucha política efectiva.

Una vez sobreseído Vargas, la violación queda suprimida definitivamente de la escena que los jueces reconstruyen e, indirectamente, obliga a la defensa a -sin dejar de afirmar que la violación efectivamente ocurrió- reformular su estrategia. De ahí que el estado mental de Romina se torne una pieza clave que será objeto de variadas especulaciones. Los argumentos de la defensa se centrarán entonces en el pedido 
de absolución basadas en la inimputabilidad de la joven. Tal condición se apoya en el padecimiento de

\begin{abstract}
(...) un stress post traumático producto de un ataque sexual (violación), que la llevó a un estado de psicosis aguda en el momento del nacimiento de la criatura. Tal estado importaba la pérdida de conciencia y la falta de comprensión de la criminalidad del acto ejecutado, vale decir, como consecuencia de ello su voluntad estaba viciada, no pudiendo dirigir sus acciones (Expte. Nro 29/05:"Romina Anahí Tejerina, homicidio calificado, San Pedro").
\end{abstract}

La defensa desarrolla entonces una explicación patologizante y psiquiatrizante, que será retomada, como vimos, por los jueces en calidad de atenuantes. La locura, el desorden mental o el vicio de la voluntad de las mujeres que comenten infanticidio se plantean, así, como elementos necesariamente presentes en la escena del delito. Y todo un cuerpo de especialistas médicos y psiquiatras, que acreditan todos ellos una notable "solvencia académica que emerge de sus antecedentes" (ídem), se abocan a confirmar o refutar tal hipótesis. La autoridad médica y el saber que de ella emana se entretejen con el discurso del derecho y conforman una red que se pretende lo suficientemente firme para explicar, vigilar y encauzar el comportamiento femenino, tan problemático como asentado en la naturaleza de un cuerpo que se plantea siempre biologizado.

Tras la condena a catorce años de prisión, la defensa interpone una serie de recursos, cuyo rechazo genera la presentación de nuevos recursos y posteriores quejas, llegando hasta la Corte Suprema de la Nación. El cuestionamiento de la sentencia impuesta a Tejerina se asentaba entonces en dos argumentos que, como dijimos, no podían ya centrarse en una violación que para la Justicia jujeña nunca tuvo lugar, sino que se sirven de la condición mental de la joven como eje. Por un lado, la defensa plantea que existió una valoración arbitraria de los elementos de prueba, precisamente en relación con los informes periciales sobre la imputabilidad de Romina, donde se sostiene que los informes de los peritos oficiales fueron arbitrariamente más valorados que los realizados por los peritos de parte. Por otro lado, se postula

\title{
(...) la existencia de un error de tipo invencible sobre la naturaleza del sujeto pasivo sobre el que recayó la acción y que llevó a la imputada a creer que había logrado un aborto en lugar de un homicidio (Rechazo de queja presentada a raíz de la denegación del "Recurso de hecho deducido por la defensa de Romina Anahí Tejerina en la causa Tejerina, Romina Anahí s/ homicidio calificado - causa Nro 29/05-").
}

Ambos argumentos se sustentan en el endeble estado psíquico de la joven (Romina es, para la defensa, inimputable) y en su incapacidad para comprender sus actos (pensó que, en lugar de estar pariendo, estaba teniendo un aborto). No obstante, si bien la queja presentada por la defensa fue desestimada por la Corte, hubo tres votos en disidencia. Resulta pertinente analizar los escritos de quienes votaron en disidencia con el fin de desentrañar la naturaleza de las objeciones allí argumentadas. Los doctores Carlos S. Fayt y E. Raúl Zaffaroni presentaron un escrito conjunto en el que cuestionan 
pormenorizadamente la valoración realizada por el Tribunal sobre los informes periciales referidos a la imputabilidad de Romina, "pues no hubo ningún intento de reconstruir el estado de la psiquis de Tejerina al momento del hecho" ${ }^{\prime 8}$.

La psiquis de Tejerina aparece aquí como objeto que debe ser desentrañado, aun en pos de su absolución. En línea con el planteo de los errores incurridos por parte de los peritos oficiales, se transcribe en el documento la siguiente cita:

\section{(...) los peritos oficiales (...) en algunas oportunidades confunden su misión con la del acusador público [...] Por más repugnancia moral y aversión personal que les produzca el delito y su autor, en ningún caso el dictamen debe dejar traslucir esos sentimientos (...) Muy a menudo, los médicos legistas convierten sus escritos en libretos acusatorios (Cabello, Vicente, Psiquiatría Forense en el Derecho Penal, Ed. Hammurabi, Buenos Aires, 2000: 639 $)$.}

El destacado es nuestro y pretende poner de relieve que los argumentos continúan partiendo del modelo de la mujer-madre-amorosa. De ahí que, pese a ser objeto de crítica en el caso de los peritos legistas, se llegue a comprender la repugnancia y aversión que las mujeres que se niegan a seguir adelante con su "natural" mandato pueden llegar a provocar.

Más adelante, se hace referencia al "modo en el que fue valorada la falta de remordimientos e insensibilidad a la que se hace alusión constante en el expediente, así como la "frialdad" con la que se manejó Tejerina con posterioridad al hecho" (el destacado es nuestro). La insensibilidad a la que se hace mención en el expediente se relaciona nuevamente con el modelo de mujer-madre que persiste en la trama discursiva que el derecho construye. De ahí que cualquier signo que denote sensibilidad o sentimientos de culpa (Ilanto, por ejemplo) en las mujeres juzgadas será positivamente valorado en los procesos judiciales, en los que impera

(...) la idea de que todas las madres deben sentir pena y dolor, cuando no culpa, frente a la muerte de su hijo. Ese imaginario entonces presenta un estereotipo cerrado, unívoco, que no permite dar cuenta de la variabilidad y la ambigüedad de los sentimientos maternales (...) [que] no son determinados por una suerte de guión psicobiológico de emociones innatas o universales, antes bien, ellas son socialmente producidas (Daich, 2008: 78-79).

Quienes la juzgaron reprochan la falta de tales signos en Tejerina, mientras que quienes disiden en rechazar su queja explican que la frialdad aludida, lejos de poder considerarse como "signo de normalidad", es el fiel "reflejo de una psiquis perturbada". De esta forma, "normalidad o anormalidad son nuevos elementos estigmatizantes y su descubrimiento como parte de la personalidad de la imputada corresponde a psicólogos

El documento completo se encuentra disponible en versión digital (Poder Judicial de la Nación, 2007).

Cabe señalar que los fallos jurídicos analizados recurren con frecuencia a referencias bibliográficas con el objetivo de validar los fundamentos expuestos mediante argumentos de profesionales especializados en la materia. 
y psiquiatras" (Caamaño Murúa y Rangel Núñez, 2002: 42). Se puede observar una constante alusión a la "doctrina especializada" con el objetivo de hacer coincidir ciertas características de Romina con las correspondientes a una "personalidad anormal". No obstante, esta operación no es (auto) reconocida como estigmatizadora, sino que, por el contrario, se coloca el componente estigmatizador del lado de quien juzga a Tejerina: se plantea que, lejos de ser consideradas como "características de una personalidad anormal" ciertas pautas presentes en la joven "fueron tenidas en cuenta con un claro sesgo peligrosista". Nos interesa remarcar que si bien esta última afirmación puede considerarse como válida, las operaciones de patologización ejercidas sobre el cuerpo y la personalidad de Romina resultan igualmente estigmatizadoras. Se plantea entonces la falta de sensibilidad en Romina como síntoma de anormalidad desde un lugar específico, que postula que

"...una mujer que es juzgada por haber querido o haber logrado matar a su hijo recién nacido encarna lo que se encumbra como lo que no debe ni debería ser. Por eso un signo de desesperación, culpa, arrepentimiento o una lágrima que se escurra, aunque sea huidiza, puede cambiar el panorama" (Kalinsky y Cañete, 2010: 45).

Al mismo tiempo, el escrito proporciona ciertas claves que nos permiten identificar una conceptualización de la juventud que responde a los modelos jurídico y represivo del poder (Chaves, 2005). Sostenemos que es posible encontrar referencias que nos remiten a un discurso psicologista sobre la juventud, aquel que la tematiza en términos de "momento de confusión, (...) como dolencia (...) (acompañado por muchas referencias al discurso médico, al modelo de la medicalización)" (Ídem: 17). En este sentido, el pronunciamiento de Fayt y Zaffaroni en el fallo plantea que

\section{(...) Incluso se han detectado durante dicha etapa [el estado puerperal] reacciones denominadas de "corto circuito", es decir reacciones que "se transforman directamente en actos sin la intervención de la personalidad total" (Vicente Cabello, Impulsividad Criminal, p. 1259). Se trata siempre de 'mecanismos reflejos susceptibles de encontrarse en cualquier comportamiento de emergencia, favorecido por ciertas personalidades deficitarias o desequilibradas' (op. cit., loc. cit.) (...) No es, entonces, de extrañar que entre los pocos ejemplos que cita quien más estudió estas cuestiones se ubica al 'infanticidio cometido por jóvenes madres' (Kretschmer, citado por Cabello en Impulsividad Criminal, el destacado es nuestro).}

El destacado es nuestro y pretende remarcar el vínculo que se establece entre psiquiatrización y juventud. Más adelante, el documento prosigue:

(...) Por lo demás, se trata de una primeriza de 19 años. El dato no es menor si se tiene en cuenta, por ejemplo, que uno de los fundamentos que utilizó la Suprema Corte de los Estados Unidos para considerar inadmisible la pena de muerte en menores (...) fue la conclusión a la que arribaron los jueces luego de examinar la información que habían presentado la Asociación Médica Americana, la Asociación de Psiquiatras Americanos y otras instituciones prestigiosas del país. Alli se señalaba que el cerebro de los menores de edad -hasta los 19/20 años- no se encuentra completamente 
desarrollado en regiones claves para la valoración y control de las conductas y la toma de decisiones (el destacado es nuestro).

Nuevamente, asistimos a la referencia al discurso médico en tanto fuente de autoridad y prestigio. Asimismo, basado en datos fisiológicos, el argumento presenta una representación de la juventud en términos de "ser incompleto, (...) [que] aparece con una tendencia mayor que otros individuos a desviarse (...) porque sus objetivos no son claros y eso también lo hace ser un sujeto peligroso" (Chaves, 2005: 15). El cerebro está incompleto y, por tanto, esto lo incapacita para dar cuenta de sus actos. Es necesario poner de relieve que este tipo de discursos y representaciones acerca de la juventud construyen un sujeto joven privado de su capacidad de agencia que, según sea la clase o sector de clase al que pertenezca, se constituirá en blanco de diferentes estereotipos y miradas estigmatizadoras (en el caso de los sectores más pobres: joven como ser desviado, peligroso, etc.). En este sentido, creemos que el escrito de Fayt y Zaffaroni encarna una práctica de intervención paternalista que, para aumentar su eficacia, se sirve de discursos estigmatizantes que producen una serie de significaciones identitarias en las que se entrecruzan el género, la clase y el componente etario.

Asimismo, nos interesa detenernos en el siguiente punto que detalla el documento:

(...) Los intentos de aborto frustrados - de los que se da cuenta en todo el expediente-, bien pudieron desencadenar una perturbación grave de la psiquis al momento de los hechos que impidió que comprendiera la criminalidad del acto (...) En efecto, es llamativo el hecho de que, contrariamente, a lo que es el instinto natural -tanto en animales como en personas - la parturienta no haya querido ni siquiera ver a la recién nacida (el destacado es nuestro).

Por un lado, consideramos que, en relación con el aborto, el argumento expuesto constituye una operación de psicologización de la problemática, en tanto postula ciertos efectos psíquicos como consecuencias de los intentos de aborto. Por el contrario, coincidimos con Fernández y Tajer en relacionar los efectos psíquicos más que con la práctica del aborto en sí, con las condiciones referidas a su "penalización y clandestinización, es decir, que tales efectos psíquicos en gran medida conciernen a las estrategias biopolíticas de disciplinamiento y control sobre los cuerpos y subjetividades de las mujeres" (2006: 35).

Es pertinente señalar que la referencia al aborto se presenta desprovista de la inherente forma de inequidad género/clase que la problemática conlleva, y que más bien se refiere a un tipo de desigualdad de clase intragénero (Cháneton, 2009). Si bien la penalización y la clandestinización de la práctica del aborto es padecida, en nuestro país, por las mujeres pertenecientes a todas las clases sociales, en el caso de Romina, su condición de mujer pobre la ubica precisamente en ese lugar de frustración que el texto jurídico simplemente alude, sin explicitar que su origen parte de la carencia económica para solventar el precio de la práctica clandestina en el mercado. 
Por otro lado, luego de plantear una posible relación directa entre aborto y perturbación de la psiquis, se apela a la subversión del "instinto natural"que Romina encarna para terminar de demostrar en qué medida su psiquis se encuentra dañada, perturbada.

Como mencionamos anteriormente, tres fueron los votos en disidencia frente al rechazo de la queja interpuesta por la defensa de Romina. El tercero es el correspondiente al doctor Juan Carlos Maqueda. Nos interesa detenernos en ciertos aspectos de sus argumentos, que refuerzan lo planteado por Fayt y Zaffaroni. En primer término, encontramos la referencia a la patologización del cuerpo femenino llevada a cabo en nombre del estado puerperal, calificado como "desorden mental post parto", como "enfermedad"y también como "realidad constatada por la ciencia", que comporta una reducción de la "autonomía de la voluntad de la parturienta". Asimismo, es posible observar cómo se lleva a cabo una conceptualización del cuerpo y la psiquis de las mujeres en tanto objetos de control médico y social:

\section{(...) El silencio de la mujer, que es frecuente, lleva a algunos a denominar esta situa- ción como "síndrome del silencio". Se ha señalado que este mutismo (...) se debe al temor de la mujer a exponer sus sentimientos negativos hacia la criatura por ser contrario al rol social aceptado de madre, impidiendo así un diagnóstico preventivo para enderezar la enfermedad de la mujer (....... por estas razones se remarca la importancia del sostén social y médico sobre este tipo de desórdenes propios de la embarazada (el destacado es nuestro).}

Si bien se acepta la naturaleza social en relación con los modos de ejercer la maternidad, "los sentimientos negativos hacia la criatura" se plantean en términos de enfermedad que debe ser curada, enderezada a manos del saber médico. Si, como vimos, el cuerpo de las mujeres se ha constituido históricamente como objeto de control social, el cuerpo de las mujeres embarazadas encarna la voluntad de control llevada al extremo. Resulta interesante analizar de qué modo la tematización en términos de "síndrome del silencio" (donde la palabra "síndrome" alude, nuevamente, a cierto componente patológico) invisibiliza la inexistencia de experiencia de maternidad alguna que el silencio encarna en una biografía determinada y dentro de un contexto donde el embarazo no es deseado ni posible.

Los argumentos que forman parte integrante del discurso jurídico expuestos a lo largo de este trabajo dan cuenta de que la conceptualización de los atenuantes que definen la figura de infanticidio nos ubica en un plano que refuerza el binomio mujer-madre, basado en una idea de maternidad concebida en términos de instinto. Ello conduce a fundamentar la reducción de la pena tanto en la patologización del cuerpo de las mujeres (estado puerperal) como en el cuestionamiento sobre el ejercicio de la actividad sexual (y la deshonra que esta provoca). El infanticidio así planteado, si bien implica un beneficio práctico para las mujeres que lo cometen en cuanto a la reducción de la pena que reciben, obtura un necesario corrimiento de la cuestión en direcciones más fructíferas y necesarias: la desnaturalización de la violencia contra las mujeres, la implementación de políticas públicas relacionadas con la educación 
sexual, la despenalización del aborto, entre otras. Es decir, el punto no debiera ser si las mujeres que matan a sus hijos e hijas están necesariamente locas o si lo hacen para ocultar la deshonra que provoca una vida sexual activa, sino que la discusión para sostener una figura jurídica como el infanticidio debería avanzar en dirección a otro tipo de circunstancias atenuantes. En este sentido, proponemos el tratamiento penal de los casos de infanticidio en tanto experiencias socialmente situadas, signadas por situaciones de violencia (física y simbólica), por contextos geográficos, sociales, culturales que restringen el acceso a la educación sexual, por una justicia sexista que insiste en obstaculizar los abortos no punibles, y por médicos objetores de conciencia a quienes, sin embargo, la violencia de género no logra conmover.

Sostenemos entonces la importancia de continuar indagando acerca de la situación paradojal a la que la figura de infanticidio conduce tal como fue históricamente definida y las no pocas consecuencias que la misma engendra al interior del movimiento de mujeres. Asimismo, es en este marco donde ubicamos la necesidad de plantear alternativas superadoras de aquellas que proponen la victimización como modo de interpelar al Estado o a cualquiera de sus poderes. Si atendemos a que fue la noción de víctima-oprimida (Cepeda, 2010) la que primó en los argumentos de la defensa de Romina Tejerina, en el voto en disidencia del Dr. Zaffaroni surgen las preguntas acerca de cómo construir una estrategia que contemple la atenuación de la pena desde otro lugar. Insistimos en que la apelación a la deshonra y al estado puerperal invisibilizan tanto la violencia de género como las desigualdades materiales como condiciones de posibilidad del infanticidio. El beneficio concreto y a corto plazo que conlleva dicha figura no debería obturar la posibilidad de incluir modificaciones sustantivas que tengan en cuenta, por un lado, los modos complejos en los que se configura histórica y contextualmente la relación entre las mujeres y su sexualidad y, por el otro, la maternidad en tanto experiencia que, lejos de ser natural, es social y, por tanto, posible bajo ciertas condiciones y no otras.

Sostenemos con Laclau (2005) que los modos de nombrar encarnan la construcción discursiva de los objetos, generando así la posibilidad de construir nuevas identidades sociales a partir de la variación de una formación discursiva hegemónica. Partiendo de considerar el campo del derecho en tanto clivaje de transformaciones y construcción de nuevas legitimidades, proponemos revisar los modos de nombrar hegemónicos que históricamente han moldeado los cuerpos de las mujeres en tanto objetos problemáticos, demandantes de vigilancia y capaces de convertirse en destino de todo tipo de juicios morales. Tal es el camino que proponemos recorrer en pos de una posible y más fructífera restitución del infanticidio al Código Penal.

\section{BIBLIOGRAFÍA}

Amossy, R. y Herschberg-Pierrot, A. (2001): Estereotipos y clichés, Buenos Aires, Eudeba.

Área Queer (2007): Medios de comunicación y discriminación: desigualdad de clase y diferencias de identidades y expresiones de género y orientaciones sexuales en los 
medios de comunicación. Buenos Aires: Facultad de Filosofía y Letras, Universidad de Buenos Aires.

Barrancos, Dora (2000): "Inferioridad jurídica y encierro doméstico", en Gil Lozano, F, Ini, G. y Pita, S. (dir.): Historia de las mujeres en la Argentina. Tomo I, Colonia y Siglo XIX, pp. 111-129, Buenos Aires, Taurus.

Ben, Pablo (2000): "Cuerpos femeninos y cuerpos abyectos. La construcción anatómica de la feminidad en la medicina argentina", en Gil Lozano, F, Ini, G. y Pita, S. (dir.): Historia de las mujeres en la Argentina. Tomo I, Colonia y Siglo XIX, pp. 253-271, Buenos Aires, Taurus.

Caamaño Murúa, Carmen y Rangel Núñez, Ana C. (2002): Maternidad, feminidad y muerte. La mirada de "Los otros" frente a la mujer acusada de infanticidio, San José de Costa Rica, Editorial de la Universidad de Costa Rica.

Cepeda, Agustina (2010): "De Paulina a Romina. Abortos no punibles, derechos y justicia en América Latina" (pp. 147-168), en Álvarez, Norberto (comp.), Familias, género y después... Itinerarios entre lo público, lo privado y lo íntimo, Rosario, Prohistoria Ediciones.

Cháneton, July (2009): Género, poder y discursos sociales, Buenos Aires, Eudeba.

Chaves, Mariana (2005): "Juventud negada y negativizada: Representaciones y formaciones discursivas vigentes en la Argentina contemporánea", Última década, Nro. 23 (diciembre de 2005), Valparaíso, pp. 9-32.

Correa, Alejandra (2000): "Parir es morir un poco. Partos en el siglo XIX", en Gil Lozano, F, Ini, G. y Pita, S. (dir.): Historia de las mujeres en la Argentina. Tomo I, Colonia y Siglo XIX, pp. 193-213, Buenos Aires, Taurus.

Daich, Débora (2008): "Buena madre. El imaginario maternal en la tramitación judicial del Infanticidio", en Tarducci, M. (comp.): Maternidades en el siglo XXI, pp. 61-86, Buenos Aires, Espacio Editorial.

Diario Judicial (2005, junio 22): "Caso Romina Tejerina: Ios fundamentos de la sentencia" [on line] Disponible en: http: //www.diariojudicial.com/contenidos/2005/06/23/ noticia_0010.html [Recuperado el 15 de febrero de 2011].

Diario Judicial (2006, septiembre 9): "Tejerina no fue víctima de violación" [on line] Disponible en: http: //www.diariojudicial.com/contenidos/2006/11/10/noticia_0004. html [Recuperado el 15 de febrero de 2011].

Elizalde, Silvia (2011): "La identidad imperiosamente. Pánico sexual y estrategias de vigilancia institucional hacia jóvenes mujeres y trans", en Elizalde, Silvia (coord.): 
Jóvenes en cuestión. Configuraciones de género y sexualidad en la cultura, pp. 119-142, Buenos Aires, Biblos.

Fernández, Ana M. y Tajer, Débora (2006):"Los abortos y sus significaciones imaginarias: dispositivos políticos sobre los cuerpos de las mujeres"(Cap. I) en Checa, S. (comp.), Realidades y coyunturas del aborto. Entreel derecho y la necesidad, Buenos Aires, Paidós.

Fraser, Nancy (2002):"Política feminista en la era del reconocimiento. Una aproximación bidimensional a la justicia de género", Documento para el Programa de Formación en Género y Políticas Públicas (PRIGEPP), Facultad Latinoamericana de Ciencias Sociales (FLACSO), Buenos Aires.

Ini, M. Gabriela (2000):"Infanticidios. Construcción de la verdad y control de género en el discurso judicial", en Gil Lozano, F, Ini, G. y Pita, S. (dir.): Historia de las mujeres en la Argentina. Tomo I, Colonia y Siglo XIX, pp. 235-251, Buenos Aires, Taurus.

Kalinsky, Beatrizy Cañete, Osvaldo (2010): Madres frágiles. Un viaje al infanticidio, Buenos Aires, Biblos.

Nari, Marcela (2004):"La maternalización de las mujeres (1890-1920)"(Cap. II), en Políticas de maternidady materialismo político. Buenos Aires 1890-1940, pp. 101-170, Buenos Aires, Biblos.

Pecheny, Mario (2006):"'Yo no soy progre, soy peronista': ¿por qué es tan difícil discutir políticamente sobre aborto?", en Cáceres, C., Careaga, G., Frasca, T. y Pecheny, M. (editores), Sexualidad, estigma y derechos humanos. Desafíos para el acceso a la salud en América Latina, Lima, Universidad Cayetano Heredia.

Poder Judicial de la Nación (2007, abril 8): "Tejerina, Romina Anahí / homicidio calificado -causa Nro. 29/05- S.C. T 228 XLIII" [on line] Disponible en: http: //www.pjn. gov.ar/Publicaciones/00018/00024550.Pdf [Recuperado el 15 de febrero de 2011].

Rubin, Gayle (1986): "El tráfico de mujeres: notas sobre la 'economía política' del sexo", en Revista Nueva Antropología, año/vol. VIII, Nro. 30, México, pp. 95-145.

Segato. Rita L. (2003): Las estructuras elementales de la violencia. Ensayos sobre género entre la antropología, el psicoanálisis y los derechos humanos, Bernal, Universidad Nacional de Quilmes. 
